\title{
Dynamic Behavior of the Polished Rod for the Coalbed Methane Pumping Installations
}

\author{
Xinfu Liu ${ }^{1 *}$, Chunhua Liu ${ }^{2}$ and Yong Yang ${ }^{1}$ \\ ${ }^{1}$ College of Mechanical Engineering, Qingdao University of Technology, Shandong 266520 - PR China \\ ${ }^{2}$ College of Mechanical and Electronic Engineering, China University of Petroleum, Shandong 266580 - PR China \\ e-mail: upcdoctor@126.com - liuxinfu@qut.edu.cn \\ * Corresponding author
}

\begin{abstract}
A modern methodology has been proposed for the system design of dynamic behavior in order to provide the accurate pertinent analysis of CoalBed Methane (CBM) pumping installations. Dynamic hanging loads on polished rod can fully reflect the kinematic and dynamic characteristics of CBM pumping installations due to their combined action of the inertial hanging loads with the loads generated by vibration and hydrodynamic friction phenomena. The practical dynamometer cards were determined by computing dynamic hanging loads with the increments of stroke length. The interpretations of results show that the maximum errors of within 2\% between the calculated and measured values are obtained with the comparison of calculated hanging loads by American Petroleum Institute (API), Schafer, Gibbs and proposed method. The ratios of inertial and vibration to polished-rod load are relatively high in producing CBM wells and calculated to be $10 \%$ and $8 \%$, respectively. And the inertial and vibration hanging load ratios decrease rapidly for two-phase CBM wells. Moreover, the effect of friction loadings on polished rod is more obvious than that of inertial and vibration hanging loads for single-phase gas CBM wells. The total deformations of rod string and tubing are within $15 \%$ of polished-rod stroke length in producing CBM wells. And the dynamic loadings enhance the imbalance of hanging loads and improve the power consumption of CBM pumping installations. The total hanging loads on polished rod are variable in a large scale for the pumping prophase and single-phase water CBM wells and the variation range of dynamic hanging loads is much lower for the two-phase and single-phase gas CBM wells.
\end{abstract}

\section{INTRODUCTION}

Nowadays, the most common method of artificial lift used for CoalBed Methane (CBM) production is the sucker rod pumping installation. Sucker rod lift is used in more than 95\% of artificial lift wells by China National Petroleum Corporation (CNPC). The dynamic behavior of the polished rod is developed to illustrate the operating potential of CBM pumping installations and provide the reasonable basis for designing and selecting the pumping installations $[1,2]$. Predicting and analyzing the dynamic behavior on polished rod during CBM production is very complex by considering the wide variety of design variables available and the problem in coupling the performance of pumping installation and producing CBM well. For the present practice, many authors have developed approximate computational formulas for the computation of dynamic loadings on polished rod based on the analytic approach of conventional oil/gas fields [3-6]. And four methods available have generally been used for the operators to predict dynamic loadings on polished rod for the specific pumping installation. American Petroleum Institute (API) offered a complete solution of the rod motion problem $[7,8]$. But this method had limiting assumptions such as simplified polished rod motion and full pump. 
And the predicted values of polished rod loadings were higher than the measured ones. Schafer's method [9] was applied to the oil wells and the results showed that it could provide a basis for oil/gas field development. However, this method, if applied to the CBM wells, neglected the liquid column pressures, the behavior of rod string and the friction force. The Gibbs's method $[10,11]$ solved the partial differential equations with a numerical simulator, and considered the motion of the well liquid, the rods and the surface unit with a slipping prime mover. But this method usually solved the problems with the limit of short stroke and low pumping speed. Firu and Xing's method [12, 13] made a number simplifying assumptions including the simple harmonic motion, and neglecting well liquid inertia and damping. And this method gave a poor accuracy of maximum polished rod loading.

In those methods, the vibration behavior of rod string and the interaction forces among rod string, tubing, pump and well liquid in the wellbore. And these relationships generally modified and applied a variety of simplified assumptions and theoretical analytic approach, or just used empirical formula of conventional oil and gas fields to calculate the extreme limits of the operational parameters. Therefore, these simplified modeling procedures, if applied to the producing CBM wells, could not help one to identify the specific phenomena that occur during the production and do not give the desired results to predict dynamic behavior of the polished rod. The reason is mainly that there exists the differences between conventional gas formations and CBM well conditions [14, 15], including shallow well depth, low water production, high dynamic fluid level, short stroke and pumping speed dropping down rapidly. Another aspect to consider is that the dynamic behavior of polished rod for CBM pumping installations has not been further developed and the available procedures do not provide the desired accuracy of the system designing and its pertinent analysis. The common problems, such as large capitalized cost, non-matching equipment, catastrophic failure and sanding up, emerge in producing CBM wells and thus decrease efficiency of the pumping system.

In order to improve the efficiency of pumping system and illustrate the operating potential of CBM pumping installations, the sucker rod pumping mechanism was furnished with some type of counterbalance system. The kinematic and dynamic analysis of CBM pumping installations and polished rod loadings were developed based on the specific CBM well conditions along the rod string stretching over a wider range. And the dynamic hanging loads on polished rod at each point during the pumping stroke cycle were computed by combining the following categories of loadings: the static and inertial loads and the loads generated by vibration and hydrodynamic friction phenomena. Then the accurate dynamometer cards were determined by computing the dynamic hanging loads on polished rod for the different phases of CBM producing process.

\section{MODEL DEVELOPMENT OF POLISHED ROD LOADINGS}

The function of CBM pumping installation is to convert the rotary motion of the prime mover and gearbox to the vertical reciprocation motion of polished rod. To implement the process of design calculation, the models must be developed to describe four primary components of the polished rod loadings for producing CBM wells. They are the static hanging load, inertial hanging load, vibration loading and friction loading. And the following paragraphs present these modeling procedures of the four components.

During one complete pumping stroke cycle, the operational parameters of CBM pumping installation can be calculated as a function of time, variable which can reach peak and minimum values. The pumping stroke cycle can be divided into four phases including the deformation period of rod string and unanchored tubing, the upstroke period, the deformation period of rod string and tubing and the downstroke period. And the polished rod position, $S_{\mathrm{A}}$, velocity, $v_{\mathrm{A}}$, and its acceleration, $a_{\mathrm{A}}$, at the various crack angles $\varphi$ can be found based on the exact kinematic analysis of pumping installations $[16,17]$.

\subsection{Design Calculation of Static Hanging Loads}

The static hanging loads on polished rod are caused by the weights given by the sucker rod string $\left(F_{\mathrm{R}}\right)$ and column of well liquids $\left(F_{\mathrm{L}}\right)$ in $\mathrm{CBM}$ wellbore, and the pressures on plunger imposed by column of well liquids $\left(F_{\mathrm{H}}\right)[18,19]$.

The rod string suffers the buoyancy force of well liquid in CBM wellbore during the downstroke period, and the weight of rod string $F_{\mathrm{R}}^{\prime}$ can be calculated as the product of the rod weight of unit length in well liquid, $q_{\mathrm{R}}^{\prime}$, and the total rod length, $L$. The polished rod suffers the hanging loads which are caused by the weights of column of well liquids in the wellbore $F_{\mathrm{L}}$ during the upstroke period. Besides, the polished rod suffers the hanging loads caused by the pressure drop at the level of CBM pumping installation (rod string and pump). The fixed valve of downhole pump is unfolded and the pressures on plunger are imposed by the column of gas and water during the upstroke period. However, the fixed valve is closed down and there are no hydraulic forces on the plunger during the downstroke period. Then the gross fluid loads $F_{\mathrm{H}}$ acting on the plunger can be found by the formulae given below:

$$
F_{\mathrm{H}}=A_{\mathrm{H}}\left(\rho_{\mathrm{m}} \mathrm{g} h_{\mathrm{C}}+p_{\mathrm{G}}\right)
$$

Therefore, the static hanging loads can be calculated in terms of the loads mentioned above. And the variation of 
static hanging loads during the upstroke, $F_{\mathrm{JS}}$, and the downstroke, $F_{\mathrm{JX}}$, as a function of the length $L$ and pressure $p_{\mathrm{G}}$ can be computed as described below:

$$
\left\{\begin{array}{c}
F_{\mathrm{JS}}=q_{\mathrm{R}} \mathrm{g} L+\left(A_{\mathrm{H}}-A\right) \rho_{\mathrm{w}} \mathrm{g} L-A_{\mathrm{H}}\left(\rho_{\mathrm{m}} \mathrm{g} h_{\mathrm{C}}+p_{\mathrm{G}}\right) \\
F_{\mathrm{JX}}=F_{\mathrm{Z}}^{\prime}=q_{\mathrm{R}}^{\prime} \mathrm{g} L
\end{array}\right.
$$

where $A, A_{\mathrm{H}}$ are the cross-sectional areas of rod and plunger, respectively, $h_{\mathrm{C}}$ is the submergence depth in wellbore, $p_{\mathrm{G}}$ is the pressure on dynamic fluid level, $q_{\mathrm{Z}}$ is the rod weight of unit length, and $\rho, \rho_{\mathrm{m}}, \rho_{\mathrm{w}}$ are the densities of rod, fluid in annular and well liquid, respectively.

\subsection{Design Calculation of Inertial Hanging Loads}

The inertial hanging loads on polished rod are the loads which the polished rod suffers during the pumping stroke cycle $[20,21]$. The inertial hanging loads are mainly caused by the moving weights given by the sucker rod string and column of well liquids in CBM wellbore. And the inertial forces can be calculated as the product of the moving weights and the polished-rod acceleration. Column of well liquids makes the motion following with polished rod during the upstroke period, while it does not move with polished rod during the downstroke period. Consequently, the inertial hanging loads on the upstroke, $F_{\mathrm{QS}}$, and the downstroke, $F_{\mathrm{QX}}$, as a function of the length $L$ and acceleration $a_{\mathrm{A}}$ can be determined by the formulae given below:

$$
\left\{\begin{array}{c}
F_{\mathrm{QS}}=\rho A\left[1+\frac{\rho_{\mathrm{w}}}{\rho} \times \frac{\left(A_{\mathrm{H}}-A\right)^{2}}{A\left(A_{\mathrm{G}}-A\right)}\right] a_{\mathrm{A}} L \\
F_{\mathrm{QX}}=\rho A a_{\mathrm{A}} L
\end{array}\right.
$$

The inertial hanging loads of column of well liquids in $\mathrm{CBM}$ wellbore, $F_{\mathrm{QL}}$, can be calculated as follows:

$$
F_{\mathrm{QL}}=\frac{A_{\mathrm{H}}-A}{A_{\mathrm{G}}-A} \mathrm{~g}^{-1} a_{\mathrm{A}} F_{\mathrm{R}}
$$

During the pumping stroke cycle, the polished-rod acceleration is continuously variable as a function of crank angle. And thus the magnitude and direction of inertial hanging loads are also variable which can reach peak and minimum values. The peak inertial hanging loads $F_{\mathrm{Qmax}}$ during the upstroke and downstroke period can be calculated as the sum of the mentioned loads.

$$
\left\{\begin{array}{c}
F_{\mathrm{QS} \max }=5.48 \times 10^{-3}(1+C) \frac{K}{\mathrm{~g}} F_{\mathrm{R}} n^{2} S \\
F_{\mathrm{QX} \max }=5.48 \times 10^{-3} \frac{F_{\mathrm{R}}}{\mathrm{g}} n^{2} S
\end{array}\right.
$$

where $n$ is the pumping speed, and $S$ is the polished-rod stroke length.

The factor $C$ indicates the inertial hanging load ratio of column of well liquids in CBM wellbore to sucker rod string and can be described, as follows:

$$
C=\frac{F_{\mathrm{L}}}{F_{\mathrm{R}}} \varepsilon=\frac{\rho_{\mathrm{w}}}{\rho} \frac{\left(A_{\mathrm{H}}-A\right)^{2}}{A\left(A_{\mathrm{G}}-A\right)}
$$

In order to describe the maximum polished-rod acceleration ratio of actual value $a_{\max }^{\prime}$ to ideal one $a_{\max }$, a factor $K$ is presented. This factor is just a function of structural parameters for CBM pumping installations and defined as follows:

$$
a_{\max }^{\prime}=K \times a_{\max }=\frac{1+r / l}{\sqrt{1-(r / b)^{2}}} \times \frac{\pi^{2}}{1800 b} n^{2} S_{\max }
$$

where $b$ is the distance between saddle bearing and equalizer bearing, $l$ is the length of pitman, $r$ is the length of crank, $S_{\max }$ is the maximum stroke length, and $\varepsilon$ is the area ratio of plunger to tubing.

And the factor $\varepsilon$ is given to illustrate the reduced acceleration of well liquids caused by the enlarging cross section of tubing.

\subsection{Design Calculation of Vibration Loadings}

The vibration behavior of sucker rod string is complex. The vibration loadings are the results of changes in acceleration during the pumping stroke cycle. And the rod string, belonging to elastomer, can be regarded as a long spring. The wave equation is ideal for the purpose because the problem at hand involves the propagation of waves in a continuous medium $[22,23]$. And it is a linear hyperbolic differential equation that describes the longitudinal vibrations of a long slender rod string. Then the vibration of sucker rod string can be approximated based on the wave equation viscous damping.

$$
\frac{\partial^{2} \mu(x, t)}{\partial t^{2}}=C_{\mathrm{E}}^{2} \frac{\partial^{2} \mu(x, t)}{\partial x^{2}}
$$

The initial and boundary conditions are defined as follows:

$$
\left\{\begin{array}{l}
\left.\mu\right|_{t=0}=0,\left.\frac{\partial \mu}{\partial t}\right|_{t=0}=-V \frac{y}{L} \\
\left.\mu\right|_{x=0}=0,\left.\quad \frac{\partial \mu}{\partial x}\right|_{x=L}=0
\end{array}\right.
$$


where $C_{\mathrm{E}}$ is the propagation velocity of elastic longitudinal wave, $t$ is the deformation time of rod string, $V$ is the relative velocity for the lower end of rod string, and $x$ is the length of rod string.

Based on the separation of variables, the solution of the wave equation with the limits of the initial and boundary conditions can be determined as follows:

$$
\begin{aligned}
\mu(x, t)= & \frac{-8 V}{\omega_{0} \pi^{2}} \sum_{n=0}^{\infty} \frac{(-1)^{n}}{(2 n+1)^{3}} \sin (2 n+1) \omega_{0} t \\
& \times \sin \left(\frac{2 n+1}{2} \times \frac{\pi x}{L}\right)
\end{aligned}
$$

Then the motion of sucker rod string can be evaluated and the vibration loads, $F_{\mathrm{V}}$, can be calculated by the following equation.

$$
\begin{aligned}
F_{\mathrm{V}} & =-\left.E A \frac{\partial \mu}{\partial x}\right|_{y=0} \\
& =0.81 \frac{E A V}{C_{\mathrm{E}}} \sum_{n=0}^{\infty} \frac{(-1)^{n}}{(2 n+1)^{2}} \sin (2 n+1) \omega_{0} t
\end{aligned}
$$

where $E$ is the elastic modulus of rod material, and $\omega_{0}$ is the circular frequency.

The vibration of sucker rod string results in a positive net loading on polished rod during the upstroke period and a negative loading during the downstroke period. And the vibration loads gradually decrease during the pumping stroke cycle because of the resistance in CBM wellbore. And thus the peak vibration load $F_{\mathrm{V} \max }$ caused by unconstrained longitudinal vibration occurs where $\omega_{0} t=0.5 \pi$ during the deformation period of rod string and tubing and can be calculated by the formulae given below:

$$
\begin{aligned}
F_{\mathrm{V} \max }=0.105 \frac{n L A}{C_{\mathrm{E}}}[ & \left(F_{\mathrm{JS}}-F_{\mathrm{JX}}\right)\left(\frac{1}{A}+\frac{1}{A_{\mathrm{W}}}\right) \\
& \left.-\frac{\rho(C K+K+1)}{365} n^{2} S L\right]
\end{aligned}
$$

where $A_{\mathrm{G}}, A_{\mathrm{W}}$ are the cross-sectional area and wall area of tubing, respectively.

\subsection{Design Calculation of Friction Loadings}

The friction loadings on polished rod are composed of the interaction forces among sucker rod string, tubing, pump and well liquid in CBM wellbore. The interaction forces between sucker rod string and tubing, $F_{1}$, are within $1.5 \%$ of the rod weights based on the statistic data for the producing CBM wells. And the semi-dry friction forces between the plunger and pump barrel, $F_{2}$, can be approximately determined by the formulae $[24,25]$. And the friction forces, $F_{3}$, are caused by the rod string and well liquid during the downstroke period [26]. The maximum value can be determined in terms of polished-rod stroke length $S$ and the viscosity of well liquid $\mu_{\mathrm{w}}$.

$$
\begin{gathered}
F_{3}=0.33 \mu_{\mathrm{w}} \frac{K_{1}^{2}-1}{\left(K_{1}^{2}+1\right) \ln K_{1}-\left(K_{1}^{2}-1\right)} \operatorname{LnS} \\
\mu_{\mathrm{w}}=8.06 \times 10^{-7} \frac{d_{\mathrm{f}}}{v} \times \frac{A_{\mathrm{H}}}{A_{\mathrm{f}}} n S
\end{gathered}
$$

The interaction forces between the tubing and well liquid, $F_{4}$, are caused by their relative movements during the upstroke period. And the friction forces are less than $77 \%$ of the forces $F_{3}$, while mostly water comprises the main component of well liquid and the viscosity of water is much lower than that of oil in the wellbore. The forces caused by pressure drops across the pump valves, $F_{5}$, are the main reasons for generating flexural deformation of rod string.

The Reynolds number [27, 28], $R e$, for the flow of well liquid in the wellbore and the draught loss, $s$, caused by the flow through pump valve can be given by:

$$
\begin{gathered}
s=1.40 \times 10^{-4} \frac{1}{\mu_{\mathrm{w}}^{2}} \times \frac{A_{\mathrm{H}}^{2}}{A_{\mathrm{f}}^{2}}(n S)^{2} \\
R e=5.24 \times 10^{-2} \frac{d_{\mathrm{f}}}{v} \frac{A_{\mathrm{H}}}{A_{\mathrm{f}}} n S
\end{gathered}
$$

Upon integration, the friction forces $F_{5}$ can be determined by the following equations.

$$
F_{5}=1.37 \times 10^{-3} \frac{\rho_{\mathrm{w}}}{\mu_{\mathrm{w}}^{2}} \times \frac{A_{\mathrm{H}}^{3}}{A_{\mathrm{f}}^{2}}(n S)^{2}
$$

Well liquid in CBM wellbore is moving with sucker rod string during the upstroke period and against the rod string during the downstroke period. Moreover, the mechanical friction loadings oppose the movement of sucker rod string, and thus the values of these forces are positive on the upstroke and negative on the downstroke. Therefore, the peak friction loadings during the upstroke period, $F_{\mathrm{MS}}$, increase the polished rod loadings and can be determined as the sum of the loads, $F_{1}, F_{2}$, and $F_{4}$, while these loadings during the downstroke period, $F_{\mathrm{MX}}$, decrease the polished rod loadings and are 
calculated as the sum of the loads, $F_{1}, F_{2}, F_{3}$, and $F_{5}$, as follows:

$$
\left\{\begin{aligned}
F_{\mathrm{MS}}= & 1.5 \% F_{\mathrm{R}}+\frac{0.94 D_{\mathrm{H}}}{\delta}-140 \\
& +\frac{0.253 \mu_{\mathrm{w}}\left(K_{1}^{2}-1\right)}{\left(K_{1}^{2}+1\right) \ln K_{1}-\left(K_{1}^{2}-1\right)} L n S \\
F_{\mathrm{MX}}= & 1.5 \% F_{\mathrm{R}}+\frac{0.94 D_{\mathrm{H}}}{\delta}-140 \\
& +\frac{0.329 \mu_{\mathrm{w}} L\left(K_{1}^{2}-1\right) n S}{\left(K_{1}^{2}+1\right) \ln K_{1}-\left(K_{1}^{2}-1\right)}+1.37 \\
& \times 10^{-3} \frac{\rho_{\mathrm{w}}}{\mu_{\mathrm{w}}^{2}} \frac{A_{\mathrm{H}}^{3}}{A_{\mathrm{f}}^{2}}(n S)^{2}
\end{aligned}\right.
$$

where $A_{\mathrm{f}}$ is the area of valve ball, $d_{\mathrm{f}}$ is the diameter of valve ball, $D_{\mathrm{H}}$ is the plunger diameter, $K_{1}$ is the diameter ratio of tubing to rod, $\delta$ is the single-sided interstice, and $v$ is the kinematic viscosity.

\section{VARIATION OF DYNAMIC HANGING LOADS}

\subsection{Design Calculation of Total Hanging Loads}

A sum of the above mentioned loadings give the total hanging loads on polished rod for CBM pumping installations. An examination of the total hanging loads on polished rod during one complete pumping stroke cycle shows that the polished rod is exposed to a cyclic loading due to the effects of well liquid flow and the conditions along the tubing stretching over a wider range. The tension levels increase with the lifted rod string and column of well liquids, inertial hanging loads, vibration loadings and friction loadings during the upstroke period. And the downstroke hanging loads consist of the buoyant weight of rod strings minus inertial hanging loads, vibration loadings and friction loadings.

Therefore, the total hanging loads on polished rod are variable and can reach peak values $F_{\max }$ and minimum ones $F_{\min }$. And the extreme values can be found by the formulae given below:

$$
\left\{\begin{array}{l}
F_{\text {max }}=F_{\mathrm{JS}}+F_{\mathrm{QS} \max }+F_{\mathrm{V} \max }+F_{\mathrm{MS}} \\
F_{\text {min }}=F_{\mathrm{JX}}-F_{\mathrm{QX} \max }-F_{\mathrm{V} \max }-F_{\mathrm{MX}}
\end{array}\right.
$$

\subsection{Design Calculation of Plunger Stroke}

During the pumping stroke cycle, the top dead center and bottom dead center are the transition points between the upstroke and downstroke. And the loads, which the rod string and tubing suffer, change between the loads $F_{\mathrm{JS}}$ and $F_{\mathrm{JX}}$. Consequently, the deformations of sucker rod string and the unanchored tubing are caused at the beginning of the upstroke and downstroke. In order to evaluate the deformation, the static deformation is introduced and can be calculated as the sum of the deformation of rod string, $\lambda_{\mathrm{C}}$, and the deformation of tubing, $\lambda_{\mathrm{G}}$, as follows:

$$
\lambda=\lambda_{\mathrm{C}}+\lambda_{\mathrm{G}}=\frac{L}{E} \times \frac{A+A_{\mathrm{W}}}{A A_{\mathrm{W}}}\left(F_{\mathrm{JS}}-F_{\mathrm{JX}}\right)
$$

The sucker rod string is exposed to a cycle loading during the pumping stroke cycle. And the tension level decreases in the end of the upstroke and increases in the end of the downstroke due to the peak inertial hanging loads. The dynamic deformation of sucker rod string, $\lambda_{1}+\lambda_{2}$, would cause additional stroke length and can be determined as follows:

$$
\lambda_{1}+\lambda_{2}=2.80 \times 10^{-4} \frac{C K+K+1}{E A} F_{\mathrm{R}} n^{2} S L
$$

During the pumping stroke cycle, the downhole plunger stroke length decreases with the static deformation $\lambda$, while the plunger stroke length increases with the dynamic deformation $\lambda_{1}+\lambda_{2}$. Therefore, the plunger stroke length, $S_{\mathrm{Y}}$, can be evaluated in terms of pumping speed, $n$, plunger area, $A_{\mathrm{H}}$, and polished-rod stroke length, $S$, as follows:

$$
\begin{aligned}
S_{\mathrm{Y}}= & S-9.81\left(\frac{A_{\mathrm{H}}}{A}+\frac{A_{\mathrm{H}}}{A_{\mathrm{W}}}\right) \frac{\rho_{\mathrm{w}}}{E} L^{2}+2.74 \\
& \times 10^{-3} \frac{(C K+K+1) \rho}{E} n^{2} S L^{2}
\end{aligned}
$$

\subsection{Determination of Dynamometer Cards}

The dynamometer card $[29,30]$ is presented by taking into account the variation of the static and inertial hanging loads, the loadings generated by the vibration and hydrodynamic friction phenomena, and the deformations of rod string and tubing. And thus it is the representation of the total hanging loads as a function of crank angle during one complete stroke cycle and used for determining CBM pumping unit loadings and the downhole pump operations.

The dynamometer cards measured by dynamometers can give approximately measurement while the CBM wells are shallow and the pumping speeds of installations are low in the coalfields. However, with the increase of the depth for producing CBM wells, it is indispensable to obtain the dynamometer cards based on the proposed modeling method. The accurate dynamometer cards can be given by taking into account the dynamic hanging loads on polished rod for CBM pumping installations and could be able to satisfy the requirements for the different phases of CBM producing process. 


\section{APPLICATION AND INTERPRETATION}

\subsection{Field Application}

The predictive formulas given above are used in conjunction with results of the numerical solution of the model equations to generate design parameters. And the application characteristics of this design calculation are demonstrated by the examples of eight producing CBM wells in Sanjiao coalfield of Ordos Basin and Zhengzhuang coalfield of Qinshui Basin. These selected CBM wells make continuous production after their completion and fracturing, and accumulate plenty of operational data. The pumping mode about CYJ3-1.5-6.5HY is widely used for the pumping installations in those producing CBM wells. And the geometry for the representative pumping mode in Zhengzhuang and Sanjiao coalfields is characterized by the parameters respectively: the crank length, $625 \mathrm{~mm}$ and $650 \mathrm{~mm}$; the pitman length, $2625 \mathrm{~mm}$ and $2600 \mathrm{~mm}$; the distance between the saddle bearing and equalizer bearing, $1325 \mathrm{~mm}$ and $1400 \mathrm{~mm}$; the distance between saddle bearing and polished rod, $1450 \mathrm{~mm}$ and $1500 \mathrm{~mm}$; the distance between beam counterbalance and saddle bearing, $2030 \mathrm{~mm}$ and $2100 \mathrm{~mm}$; the distance between crank shaft and saddle bearing, $3150 \mathrm{~mm}$ and $3200 \mathrm{~mm}$; the beam counterweights, $15.0 \mathrm{kN}$ and $16.0 \mathrm{kN}$; the crank counterweights, 0 .

Based on the characteristics of gas and water flow in $\mathrm{CBM}$ reservoirs, the complete producing process can be divided into four phases including pumping prophase, single-phase water flow, two-phase (gas and water) flow and single-phase gas flow [31, 32]. As is known, the operational parameters that might influence dynamic hanging loads on polished rod in producing CBM wells are furnished for the proposed design method. The above operational parameters and independent variables are selected for the CBM pumping installations studied in Zhengzhuang and Sanjiao coalfields and presented in Table 1. These independent variables are given in order to illustrate the calculation of the design objective function for the dynamic behavior of the polished rod.

\subsection{Results and Interpretations}

Figure 1 describes the variation of polished-rod position, velocity and its acceleration vs. crank angle with the geometry of the selected CBM pumping installations in Sanjiao coalfield. The curve of $S_{\mathrm{A}} / S_{\max }$ represents the polished-rod position as a function of crank angle with the cosine form. The curve of $v_{\mathrm{A}} /\left(\omega S_{\max }\right)$ is a plot of the polished-rod velocity function as it varies with the form of a sinusoidal curve. The geometry of the pumping installation is such that the value of rotational acceleration for the crank in a clockwise direction is larger than that in a counter clockwise direction with the same increments of crank angle. While the wellhead is in the right of the pumping installation, the cranks should rotate in a counter clockwise direction in order to decrease the maximum polished-rod acceleration during the upstroke period.

The dynamic hanging loads on polished rod are determined by applying the relationships developed based on the measured parameters and independent variables. And the extreme values of above mentioned loadings are obtained with the help of solution of the model procedures and the results are given in Table 2. Notice that the results during the different phases of CBM producing process show that the static hanging loads play a major role on polished rod for the pumping installations. The ratio of static to polished-rod load increases with the reduced pumping speeds. And the average load ratios increase from $82.0 \%$ up to $93.0 \%$ in the selected eight producing CBM wells in Zhengzhuang and Sanjiao coalfields.

Figure 2 is a plot of the dynamic hanging load function as it varies with the pumping speed for the different phases of CBM producing process. And the parameter that is a function of dynamic hanging load ratio has been introduced. The dynamic hanging loads on polished rod can fully reflect kinematic and dynamic characteristics of CBM pumping installations due to their combined action of the inertial hanging loads, vibration loadings and friction loadings. Figure 2 shows that compared with conventional oil and gas fields, the ratios of inertial and vibration to polishedrod load are relatively high in producing CBM wells. And thus the effect of inertial hanging loads and vibration loadings cannot be neglected while predicting and analyzing dynamic behavior of the polished rod. And the average ratios of inertial hanging loads decrease rapidly from $9.0 \%$ during the pumping prophase to $5.0 \%$ for single-phase water CBM wells, and then to $3.0 \%$ for two-phase (gas and water) CBM wells in Zhengzhuang and Sanjiao coalfields. Moreover, the average ratios of vibration loadings decrease rapidly from $6.0 \%$ during the pumping prophase to $3.0 \%$ for two-phase CBM wells. Furthermore, the load ratio of friction to polished rod is also relatively high and cannot be neglected for producing CBM wells. And for the single-phase gas CBM wells, the effect of friction loadings on polished rod is more obvious than that of inertial hanging loads and vibration loadings due to the poor friction characteristics of well liquid in CBM wellbore. The average ratios of friction loadings vary from $3.5 \%$ up to $4.0 \%$, and at the end to $5.0 \%$ in the selected eight producing CBM wells.

Figure 3 features the deformations as a function of pumping speed for the different phases of CBM producing process. And the parameter that is a function of the deformation ratio has been introduced. Compared with conventional oil and gas fields, the total hanging loads on polished rod are relatively small, which makes the total deformations of rod 
TABLE 1

Operational parameters and independent variables for the different phases of CBM producing process in Zhengzhuang and Sanjiao coalfields.

\begin{tabular}{|c|c|c|c|c|c|c|c|c|}
\hline \multirow{3}{*}{$\begin{array}{c}\text { Parameter } \\
\text { Rod diameter } d(\mathrm{~mm})\end{array}$} & \multicolumn{8}{|c|}{ Values } \\
\hline & \multicolumn{4}{|c|}{ Zhengzhuang coalfield } & \multicolumn{4}{|c|}{ Sanjiao coalfield } \\
\hline & 19.0 & 19.0 & 19.0 & 19.0 & 19.0 & 19.0 & 19.0 & 19.0 \\
\hline Tubing diameter $D(\mathrm{~mm})$ & 52.4 & 52.4 & 52.4 & 52.4 & 73.02 & 73.02 & 73.02 & 73.02 \\
\hline Cross-sectional area of tubing $A_{\mathrm{G}}\left(\mathrm{cm}^{2}\right)$ & 19.87 & 19.87 & 19.87 & 19.87 & 41.87 & 41.87 & 41.87 & 41.87 \\
\hline Wall thickness of tubing $D_{\mathrm{W}}(\mathrm{mm})$ & 3.96 & 3.96 & 3.96 & 3.96 & 7.82 & 7.82 & 7.82 & 7.82 \\
\hline Plunger diameter $D_{\mathrm{H}}(\mathrm{mm})$ & 44 & 44 & 44 & 44 & 56 & 56 & 56 & 56 \\
\hline Dynamic fluid level $H(\mathrm{~m})$ & 610 & 671 & 695 & 701 & 457 & 545 & 631 & 649 \\
\hline Density of well liquid in annular $\rho_{\mathrm{m}}\left(\mathrm{kg} \cdot \mathrm{m}^{-3}\right)$ & 956 & 833 & 486 & 778 & 970 & 856 & 512 & 765 \\
\hline Density of well liquid $\rho_{\mathrm{w}}\left(\mathrm{kg} \cdot \mathrm{m}^{-3}\right)$ & 1016 & 1015 & 1013 & 1012 & 1016 & 1014 & 1014 & 1013 \\
\hline Viscosity of well liquid $\mu_{\mathrm{w}}(\mathrm{mPa} \cdot \mathrm{s})$ & 0.79 & 0.79 & 0.79 & 0.79 & 0.82 & 0.82 & 0.82 & 0.82 \\
\hline Pumping speed $n\left(\mathrm{r} \cdot \min ^{-1}\right)$ & 10.0 & 7.0 & 4.5 & 2.0 & 9.0 & 6.5 & 3.8 & 2.4 \\
\hline
\end{tabular}

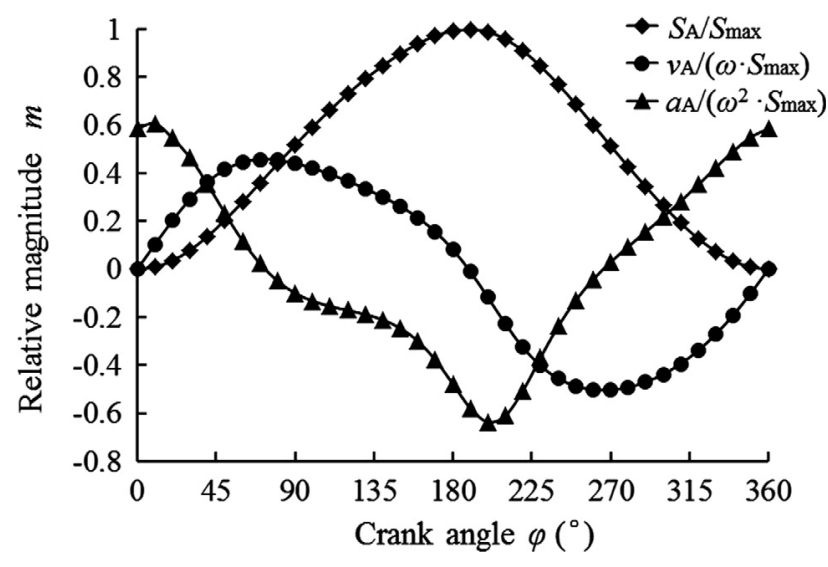

Figure 1

The variation of polished-rod position, velocity and acceleration for CBM pumping installations.

string and tubing are much smaller in producing CBM wells. Figure 3 contains the statistical ratio of the total deformation to polished-rod stroke length indicating an overall ratio of $11.5 \%$ and individual ratio as high as $13.5 \%$ for the selected eight producing CBM wells. Moreover, the static deformation plays a major role while the dynamic deformation is relatively small in the total deformation of rod string and tubing. The overall ratios of static deformation to stroke length increase from $9.5 \%$ up to $14.0 \%$, while the average ratios of dynamic deformation to stroke length decrease from $2.0 \%$ during the pumping prophase to $0.4 \%$ for two-phase (gas and water) CBM wells, and then to $0.08 \%$ for single-phase gas CBM wells in Zhengzhuang and Sanjiao coalfields.
And the dynamic deformation is so small that its effect on the total deformation can be neglected for the two-phase and single-phase gas CBM wells.

Evaluation of the accuracy of applying this approach developed is made possible with the use of measured well data from the coalfields. The percent error between the measured and calculated total loadings on polished rod in the API, Schafer, Gibbs and proposed method are shown in Table 3. The maximum percent errors for the four methods are calculated to be $-33 \%,-35 \%,-17 \%$, and $-1.3 \%$, respectively. And the average percent errors are determined to be $13 \%, 14 \%, 10 \%$, and $0.7 \%$, respectively. And thus the proposed method would reduce the average percent error by $12 \%, 13 \%$, and $9 \%$, respectively. Therefore, the present design method for CBM wells mainly applied the previous design methods in oil and gas fields, and the available procedures cannot provide the desired accuracy of the loading design and its pertinent analysis of dynamic behavior in CBM producing wells. And the results of the present methods give the polished rod larger hanging loads than the proposed method which would dictate for CBM pumping conditions examined. Then it will make the downhole pumps the most likely to fail and enhance the energy requirements of the whole pumping systems. At the same time, the statistical case truly indicates how much the variation of the fluid loads acting on the plunger, rod string loadings generated by vibration and hydrodynamic friction phenomena can reduce the error in the computation of dynamic hanging loads on the polished rod.

The dynamometer cards presented in Figure 4 are the plots of dynamic hanging loads on the polished rod for 
TABLE 2

The results of dynamic hanging loads on polished rod for the different phases of CBM producing process in Zhengzhuang and Sanjiao coalfields.

\begin{tabular}{|c|c|c|c|c|c|c|c|c|c|c|}
\hline \multirow[b]{2}{*}{ Stroke } & \multicolumn{5}{|c|}{ Zhengzhuang coalfield } & \multicolumn{5}{|c|}{ Sanjiao coalfield } \\
\hline & $\begin{array}{c}\text { Static } \\
\text { load } \\
F_{\mathrm{J}}(\mathrm{kN})\end{array}$ & $\begin{array}{c}\text { Inertial } \\
\text { load } \\
F_{\mathrm{Q}}(\mathrm{kN})\end{array}$ & $\begin{array}{c}\text { Vibration } \\
\text { load } \\
F_{\mathrm{V}}(\mathrm{kN})\end{array}$ & $\begin{array}{c}\text { Friction } \\
\text { load } \\
F_{\mathrm{M}}(\mathrm{kN})\end{array}$ & $\begin{array}{c}\text { Total } \\
\text { load } \\
F(\mathrm{kN})\end{array}$ & $\begin{array}{c}\text { Static } \\
\text { load } \\
F_{\mathrm{J}}(\mathrm{kN})\end{array}$ & $\begin{array}{c}\text { Inertial } \\
\text { load } \\
F_{\mathrm{Q}}(\mathrm{kN})\end{array}$ & $\begin{array}{c}\text { Vibration } \\
\text { load } \\
F_{\mathrm{V}}(\mathrm{kN})\end{array}$ & $\begin{array}{c}\text { Friction } \\
\text { load } \\
F_{\mathrm{M}}(\mathrm{kN})\end{array}$ & $\begin{array}{c}\text { Total } \\
\text { load } \\
F(\mathrm{kN})\end{array}$ \\
\hline \multirow{4}{*}{ Upstroke } & 24.05 & 2.75 & 1.43 & 0.91 & 29.14 & 22.42 & 2.17 & 1.76 & 1.11 & 27.46 \\
\hline & 24.29 & 1.35 & 0.96 & 0.90 & 27.50 & 24.24 & 1.14 & 1.20 & 1.10 & 27.69 \\
\hline & 22.53 & 0.56 & 0.54 & 0.90 & 24.53 & 26.67 & 0.39 & 0.82 & 1.09 & 28.98 \\
\hline & 23.33 & 0.11 & 0.24 & 0.89 & 24.57 & 27.31 & 0.16 & 0.59 & 1.09 & 29.16 \\
\hline \multirow{4}{*}{ Downstroke } & 14.52 & 1.39 & 1.43 & 1.34 & 10.36 & 13.50 & 1.03 & 1.76 & 1.45 & 9.26 \\
\hline & 14.52 & 0.69 & 0.96 & 1.11 & 11.76 & 13.50 & 0.54 & 1.20 & 1.28 & 10.48 \\
\hline & 14.52 & 0.28 & 0.54 & 0.99 & 12.71 & 13.50 & 0.19 & 0.82 & 1.17 & 11.32 \\
\hline & 14.52 & 0.06 & 0.24 & 0.91 & 13.31 & 13.50 & 0.08 & 0.59 & 1.13 & 11.71 \\
\hline
\end{tabular}

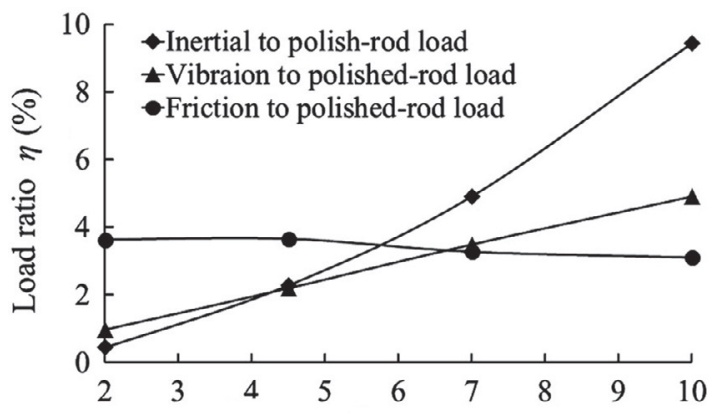

a) Pumping speed $n\left(\mathrm{r} \cdot \mathrm{min}^{-1}\right)$

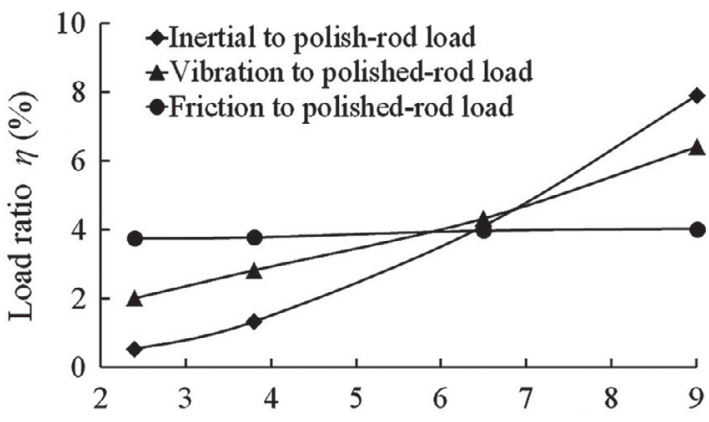

b) $\quad$ Pumping speed $n\left(r \cdot \min ^{-1}\right)$

Figure 2

The variation of dynamic hanging loads on polished rod in the producing CBM wells studied: a) Zhengzhuang coalfield, b) Sanjiao coalfield.
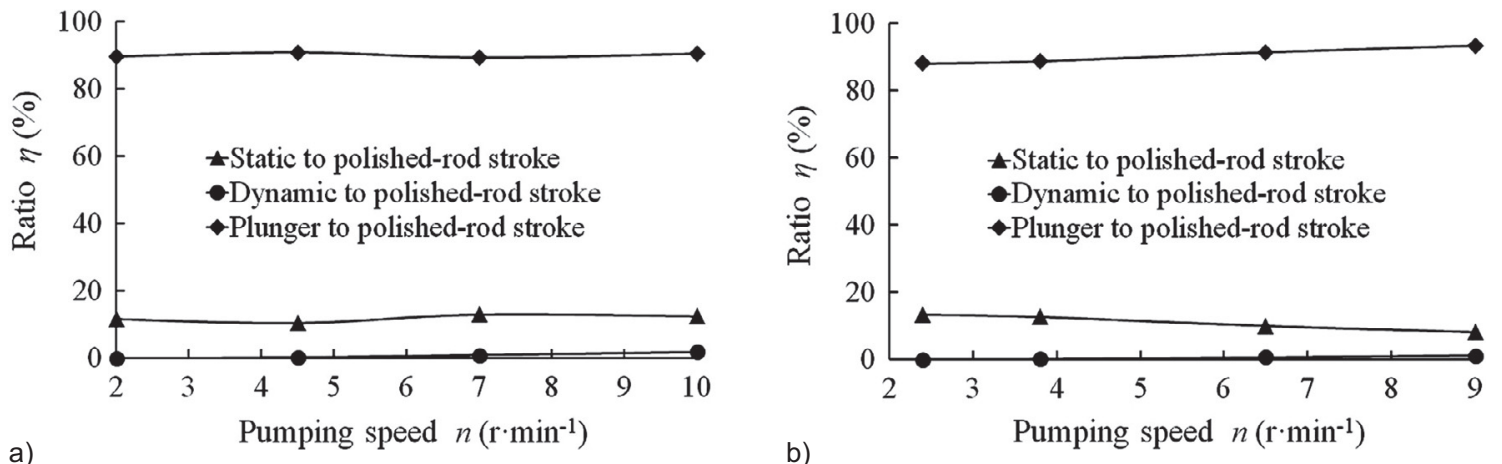

Figure 3

The variation of deformations for rod string and tubing in the producing CBM wells studied: a) Zhengzhuang coalfield, b) Sanjiao coalfield. 
TABLE 3

The errors in the different approaches to calculating dynamic hanging loads on polished rod in Sanjiao coalfield.

\begin{tabular}{|c|c|c|c|c|c|c|c|c|c|}
\hline \multirow[b]{2}{*}{ Stroke } & \multirow{2}{*}{$\begin{array}{c}\text { Measured } \\
\text { total load } \\
F^{\prime}(\mathrm{kN})\end{array}$} & \multicolumn{2}{|c|}{ API method } & \multicolumn{2}{|c|}{ Schafer's method } & \multicolumn{2}{|c|}{ Gibbs's method } & \multicolumn{2}{|c|}{ The proposed method } \\
\hline & & $\begin{array}{c}\text { Calculated } \\
\text { total load } \\
F(\mathrm{kN})\end{array}$ & $\begin{array}{l}\text { Error } \\
E(\%)\end{array}$ & $\begin{array}{c}\text { Calculated } \\
\text { total load } \\
F(\mathrm{kN})\end{array}$ & $\begin{array}{l}\text { Error } \\
E(\%)\end{array}$ & $\begin{array}{c}\text { Calculated } \\
\text { total load } \\
F(\mathrm{kN})\end{array}$ & $\begin{array}{c}\text { Error } \\
E(\%)\end{array}$ & $\begin{array}{c}\text { Calculated } \\
\text { total load } \\
F(\mathrm{kN})\end{array}$ & $\begin{array}{l}\text { Error } \\
E(\%)\end{array}$ \\
\hline \multirow{4}{*}{ Upstroke } & 27.12 & 31.07 & -14.56 & 29.95 & -10.41 & 31.75 & -17.06 & 27.46 & -1.25 \\
\hline & 27.43 & 30.04 & -9.52 & 29.45 & -7.35 & 30.96 & -12.86 & 27.69 & -0.95 \\
\hline & 28.88 & 29.29 & -1.42 & 29.09 & -0.72 & 30.10 & -4.24 & 28.98 & -0.35 \\
\hline & 29.11 & 29.06 & 0.18 & 28.97 & 0.47 & 29.66 & -1.89 & 29.16 & -0.17 \\
\hline \multirow{4}{*}{ Downstroke } & 9.37 & 12.47 & -33.08 & 12.58 & -34.30 & 9.24 & 1.41 & 9.26 & 1.17 \\
\hline & 10.58 & 12.96 & -22.50 & 13.02 & -23.09 & 9.48 & 10.36 & 10.48 & 0.99 \\
\hline & 11.37 & 13.31 & -17.06 & 13.34 & -17.30 & 9.75 & 14.25 & 11.32 & 0.45 \\
\hline & 11.74 & 13.42 & -14.31 & 13.43 & -14.44 & 9.89 & 15.77 & 11.71 & 0.30 \\
\hline
\end{tabular}
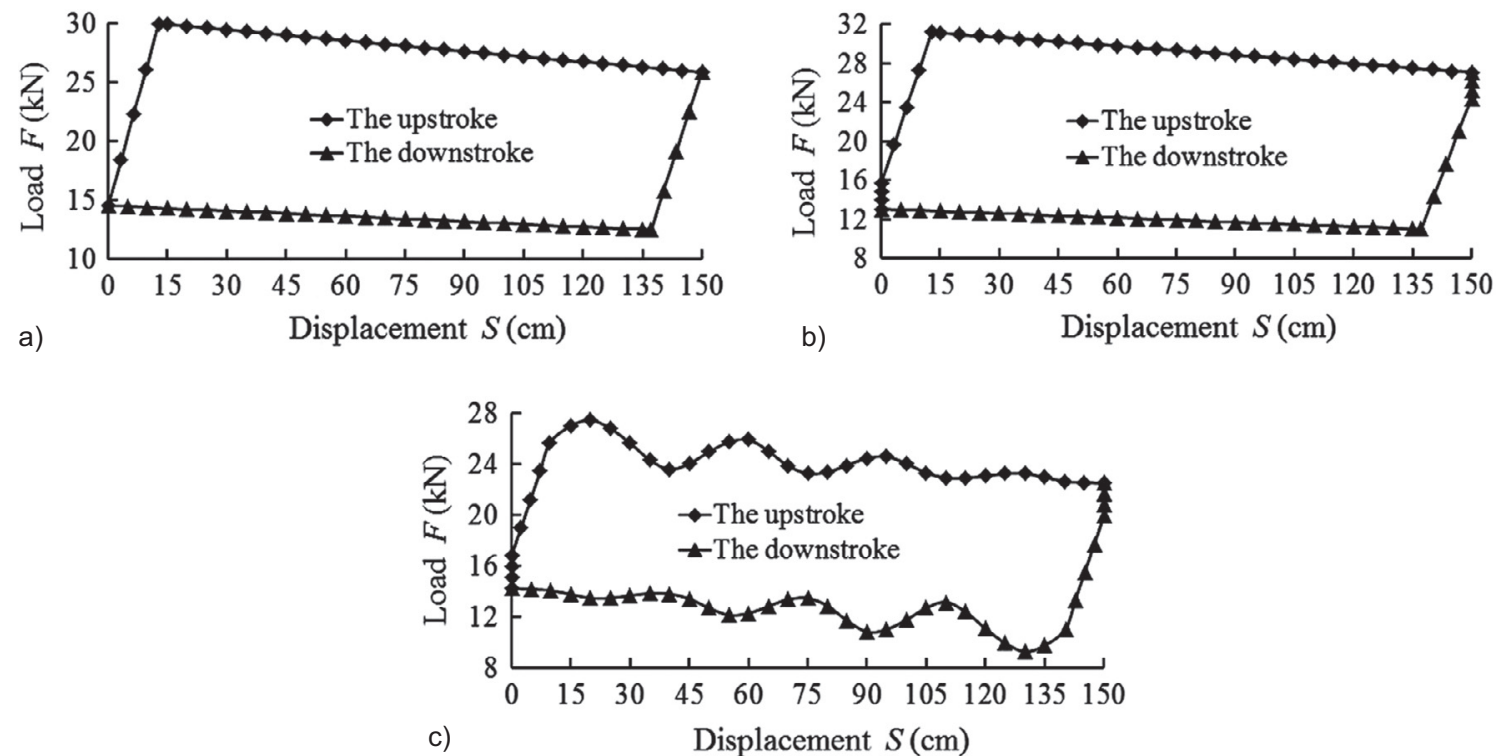

Figure 4

The dynamic hanging loads on polished rod for the four pumping stroke cycles in the producing CBM wells studied: a) calculated by Schafer's method, b) calculated by Gibbs's method, c) calculated by the proposed method.

each stroke length during the four pumping stroke cycles. The extreme loadings on polished rod calculated by Schafer's method, as shown in Figure 4a, were predicted to be $29.95 \mathrm{kN}$ and $12.58 \mathrm{kN}$, respectively. The computation of hanging loads on the polished rod involved the lifted rod string and column of well liquid and linear inertial loads, but it neglected the nonlinear inertial loads and the loadings generated by vibration and hydrodynamic friction phenomena. And the use of the modified stress resulted in the nonminimum taper designs of rod string for CBM pumping installations. The extreme loadings on polished rod determined by Gibbs's method, as shown in Figure 4b, were evaluated to be $31.75 \mathrm{kN}$ and $9.24 \mathrm{kN}$, respectively. The computation of hanging loads on the polished rod 

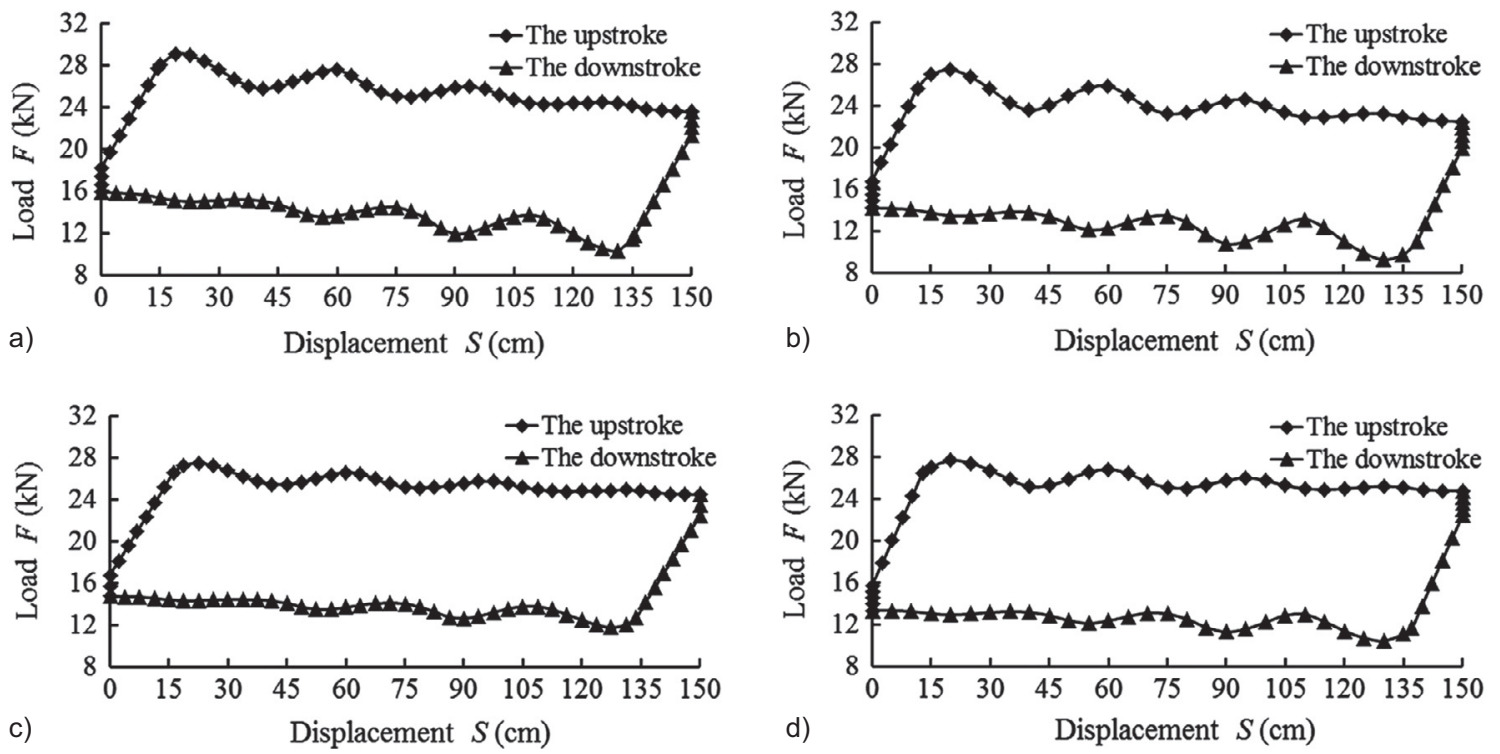

Figure 5

The surface dynamometer cards for the pumping prophase and single-phase water CBM wells: a) the pumping prophase in Zhengzhuang coalfield, b) the pumping prophase in Sanjiao coalfield, c) single-phase water flow in Zhengzhuang coalfield, d) single-phase water flow in Sanjiao coalfield.

involved the distribution of inertial hanging loads along the rod string and rod vibration proportional to the rod masses linear dynamic forces, but it neglected the disproportional loadings of vibration and friction. And the same degree of safety cannot demonstrate the cyclic nature of rod string loadings for CBM pumping installations. The peak and minimum loadings on polished rod predicted by the proposed method, as shown in Figure 4c, were calculated to be $27.46 \mathrm{kN}$ and $9.26 \mathrm{kN}$, respectively. And this figure features the dynamic hanging loads on polished rod as a function of cycle time for the four pumping stroke cycles. These dynamic hanging loads can be classified into the static hanging loads, inertial hanging loads, vibration loadings and friction loadings. The dynamic hanging loads calculated can illustrate the elastic force waves which travel in the rod string for CBM pumping installations. The waves are of different magnitude and phase and affect the actual rod forces in any section. However, the previous design on dynamic behavior disregards these hanging loads arising from such effects due to the complexity of describing these force waves. It is believed that this approach could give more realistic dynamic hanging loads than previous approximations for producing CBM wells.

Figure 5 describes the variation of dynamometer cards for the pumping prophase and single-phase water CBM wells during the producing process in the selected eight producing CBM wells. The tension levels on polished rod increase with the lifted rod string and column of well liquids, inertial hanging loads, vibration loadings and friction loadings during the upstroke period. And the downstroke hanging loads decline because the loadings of inertial, vibration and friction are always opposed to the buoyant weight of rod strings. The inertial hanging loads, vibration loadings and friction loadings enhance the imbalance of the hanging loads on polished rod and improve the power consumption of CBM pumping installations. When the difference between the peak and minimum hanging loads is large, the fatigue phenomena of the material of rod string and tubing become much more significant. The total hanging loads on polished rod are variable in a large scale due to the high flow rate of well liquid and dynamic fluid level dropping down rapidly for the pumping prophase and single-phase water CBM wells. The overall extreme values of the total hanging loads decrease from $29.2 \mathrm{kN}$ during the prophase, shown in Figure 5a and Figure $5 \mathrm{~b}$, to $28.3 \mathrm{kN}$ for the single-phase water CBM wells, given in Figures $5 \mathrm{c}$ and $5 \mathrm{~d}$, in Zhengzhuang and Sanjiao coalfields.

Figure 6 is given to illustrate the variation of dynamometer cards for the two-phase (gas and water) and single-phase gas CBM wells during the producing process in Zhengzhuang and Sanjiao coalfields. The variation range of dynamic hanging loads declines rapidly during the producing process. Compared with the pumping prophase and single-phase water CBM wells, the variation range is much lower for the two-phase and single-phase gas CBM wells while the dynamic fluid level drops down smoothly. The overall extreme values of the total hanging loads, as shown in Figure 6, decrease from $26.1 \mathrm{kN}$ for the two-phase 

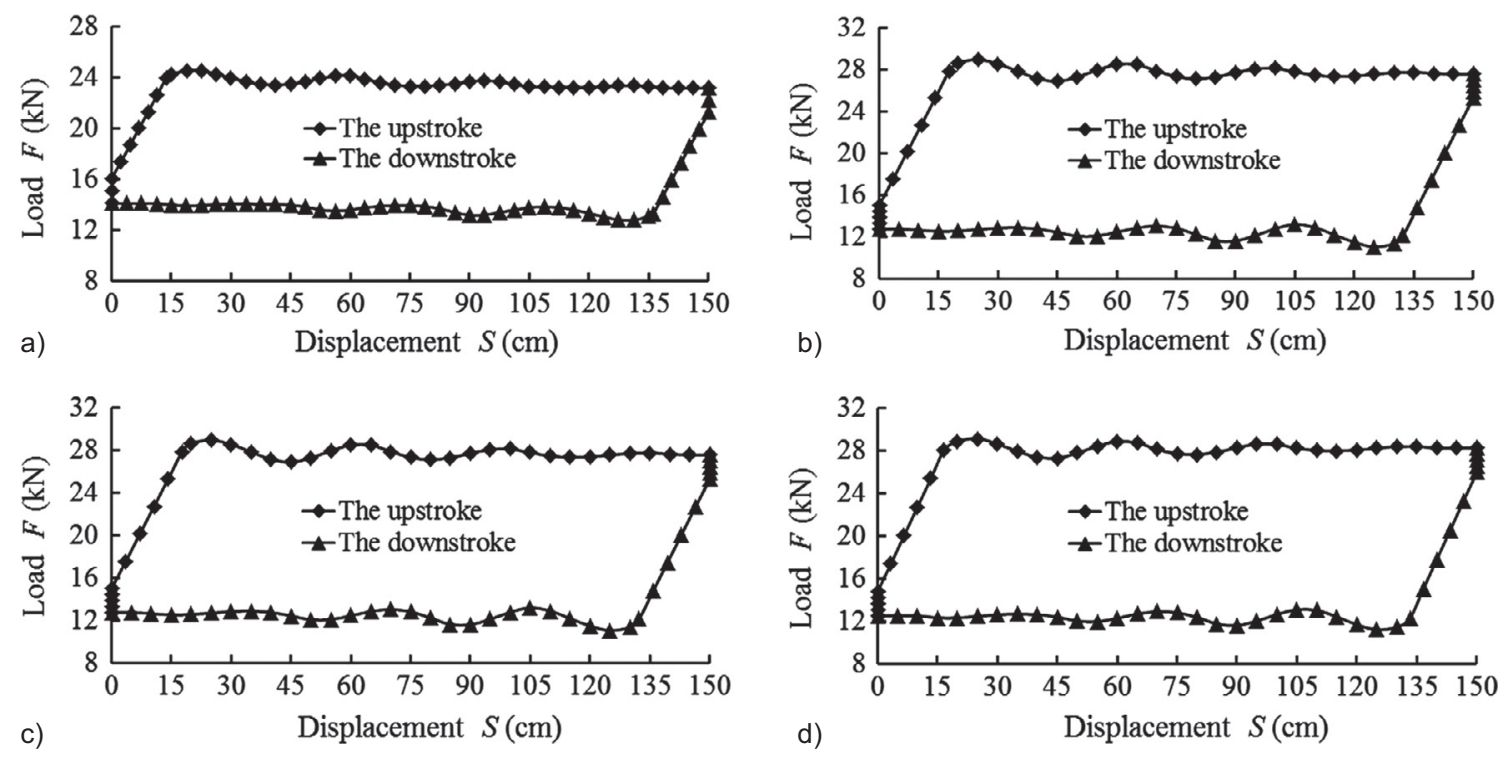

Figure 6

The surface dynamometer cards for the two-phase (gas and water) and single-phase gas CBM wells: a) two-phase flow in Zhengzhuang coalfield, b) two-phase flow in Sanjiao coalfield, c) single-phase gas flow in Zhengzhuang coalfield, d) single-phase gas flow in Sanjiao coalfield.

CBM wells to $26.0 \mathrm{kN}$ for the single-phase gas CBM wells in Zhengzhuang and Sanjiao coalfields. For the twophase and single-phase gas CBM wells, the dynamic hanging loads become much smaller due to the low pumping speed and well liquid flow rate. Moreover, the total deformation of rod string and tubing decreases for the two-phase and single-phase gas CBM wells. And the average deformation calculated is only $129 \mathrm{~mm}$ in the selected eight producing CBM wells of Zhengzhuang and Sanjiao coalfields.

It is most likely that the appropriate design of dynamic behavior for the polished rod is the one which operates the available installation at the vicinity of its limitations. Consequently, the system design of dynamic hanging loads is a mixed-integer nonlinear programming problem that requires substantial calculation. Based on the values of operational parameters and independent variables measured, the methodology proposed leads to the results of solving the common problems emerge in producing CBM wells and illustrating the operating potential of CBM pumping installations.

\section{CONCLUSION}

1. The dynamic hanging loads on polished rod can fully reflect kinematic and dynamic characteristics of CBM pumping installations due to their combined action of the inertial hanging loads, vibration loadings and friction loadings.
2. Compared with conventional oil and gas fields, the total deformations of the rod string and tubing are much smaller in producing CBM wells. And the static deformation plays a major role while the dynamic deformation is relatively small in the total deformation.

3. The inertial hanging loads, vibration loadings and friction loadings enhance the imbalance of hanging loads on the polished rod and improve the power consumption of CBM pumping installations.

4. Compared with the pumping prophase and single-phase water CBM wells, the variation range is much lower for the two-phase and single-phase gas CBM wells while the dynamic fluid level drops down smoothly.

The result of this work is the mathematical model developed and programming method proposed using for predicting and analyzing the dynamic hanging loads on polished rod in producing CBM wells. And this makes it be possible to provide the desired accuracy of the system designing and its pertinent analysis of dynamic behavior. Moreover, the mathematical programming method developed results to the reduction of the mode for CBM pumping installation and improving the efficiency of pumping system.

\section{ACKNOWLEDGMENTS}

The financial support for this study by the National Science and Technology Major Project under Award No. 2011ZX05038 and 2011ZX05062 is gratefully acknowledged. 


\section{REFERENCES}

1 Krzysztof P., Jaroslaw C. (2009) Optimizing downhole fluid production of sucker-rod pumps with variable motor speed, SPE Prod. Oper. 24, 2, 346-352.

2 Stachowiak J. (2015) New sucker rod pump technology with integral screen for sandy wells, SPE Production and Operations Symposium, 1-5 March, Oklahoma City, Oklahoma, USA.

3 Telli F.D. (2010) Increasing sucker rods' working capacities, J. Petrol. Technol. 62, 1, 26-29.

4 Zhao H.H., Qi Y.G., Du H.W., Wang N.N., Zhang G.F., Liu W.B., Lu H.L. (2016) Cloud computation processing for oilfield block data and chain drive pumping unit polished rod motion model, J. Sign. Process. Syst. 24, 8, 1-10.

5 Reges G.D., Schnitman L., Reis R., Mota F. (2015) A new approach to diagnosis of sucker rod pump systems by analyzing segments of downhole dynamometer cards, SPE Artificial Lift Conference-Latin America and Caribbean, 27-28 May, Salvador, Brazil.

6 Dumitru N., Craciunoiu N., Malciu R., Ploscaru N. (2015) Elastodynamic analysis of the sucker rod pumping system mechanism, Mech. Mach. Sci. 24, 355-363.

7 Iskenderli I.N., Kuliev I.S., Narimanov V.A., Kel'biev F.M. (2013) Analysis of efficiency of methods for improving sucker-rod deep-well pump plungers and choice of an alternative method, Chem. Petrol. Eng. 49, 7, 536-538.

8 Liu L., Tong C., Wang J., Liu R. (2004) A uniform and reduced mathematical model for sucker rod pumping, in: Bubak M., Albada G.D., Sloot P.M.A., Dongarra J. (eds), Computational ScienceICCS 2004, Springer, Berlin, Heidelberg, Vol. 3037, pp. 372-379.

9 Schafer D.J., Jennings J.W. (2012) An investigation of analytical and numerical sucker rod pumping mathematical models, SPE J. 33, 9, 405-413.

10 Gibbs S.G. (1994) Assumptions of the API rod pumping design method as related to practical applications and wave equation techniques, University of Tulsa Centennial Petroleum Engineering Symposium, 29-31 August, Tulsa, Oklahoma, USA.

11 Gibbs S.G., Nolen K.B., Morrow F.E., Lynch W.E. (1995) Monitoring and controlling rod pumped wells using downhole pump cards, SPE Annual Technical Meeting, 7-9 June, Calgary, Alberta, Canada.

12 Firu L.S., Chelu T., Petre C.M. (2003) A modern approach to the optimum design of sucker-rod pumping system, SPE Annual Technical Conference and Exhibition, 5-8 October, Denver, Colorado, USA.

13 Xing M.M., Dong S.M., Tong Z.X., Tian R.F., Chen H.L. (2015) Dynamic simulation and efficiency analysis of beam pumping system, J. Cent. South Univ. 22, 3367-3379.

14 Liu X.F. (2013) Prediction of flowing bottomhole pressures for two-phase coalbed methane wells, Acta Geol. Sin-Engl. 87, 5, 1412-1420.

15 Yao Y.D., Ge J.L. (2011) Characteristics of non-darcy flow in low-permeability reservoirs, Petrol. Sci. 8, 1, 55-62.

16 Liu X.F., Qi Y.G., Liu C.H., Liu F. (2009) Analytical method of the equipment of water pumping and gas production with the sucker-rod pump for CBM wells, Min. Proc. Eq. 37, 9, 10-13.
17 Takacs G., Kis L., Koncz A. (2016) The calculation of gearbox torque components on sucker-rod pumping units using dynamometer card data, J. Petrol. Explor. Prod. Technol. 6, 1, 101-110.

18 Wang Y.P., Wang H.W., Zhang C., Lai M.H. (2005) Computing static hanging load of sucker rod in pumping well by means of leakage curves, J. Xi'an Shiyou U. 20, 2, 58-60.

19 Liu C.H. (2015) Sucker rod string design of the pumping systems, Ingeniería e Investigación 35, 2, 6-14.

20 Hirschfeldt C.M., Ruiz R. (2009) Selection criteria for artificial lift system based on the mechanical limits: case study of Golfo San Jorge Basin, SPE Annual Technical Conference and Exhibition, 4-7 October, New Orleans, Louisiana, USA.

21 Hojjati M.H., Gittins S.A. (2005) Modelling of sucker rod string, J. Can. Petrol. Technol. 44, 12, 77-80.

22 Deng S., Fan H.H., Liu Y.H., Liu J.G., Peng Q., Ren W.Y. (2016) Study on longitudinal vibration of casing string in deep water by riserless drilling, Offshore Technology Conference Asia, 22-25 March, Kuala Lumpur, Malaysia.

23 Yang H.B., Di Q.F., Wang W.C. (2005) Prediction of serious abrasion position and mechanism of uneven abrasion between sucker rod string and tubing, Acta Petrolei Sin. 26, 2, 100-103.

24 Xu J., Shirazi S.A., Doty D.R., Prado M.G. (2000) Prediction of turbulent friction in rod-pumped wells, SPE J. 5, 2, 182-189.

25 Pons V.M. (2014) Optimal stress calculations for sucker-rod pumping systems, SPE Artificial Lift Conference \& Exhibition-North America, 6-8 October, Houston, Texas, USA.

26 Janahmadov A.K., Javadov M.Y. (2016) Fractal fatigue analysis of valve units of sucker rod pumps, Springer International Publishing, Switzerland.

27 Pan X., Wong R.C., Maini B.B. (1998) Steady state immiscible oil and water flow in a smooth-walled fracture, J. Can. Pet. Technol. 37, 5, 127-134.

28 Guichard A.M., Zhan L., Dilling L., Giaquinta A., Mohamed E.E.D., Awaad A.H. (2010) The first successful impulse test on coiled tubing, results in reliable reservoir evaluation for non-naturally flowing wells, North Africa Technical Conference and Exhibition, 14-17 February, Cairo, Egypt.

29 Schirmer P., Gay J.C., Toutain P. (1991) Use of advanced pattern-recognition and knowledge-based system in analyzing dynamometer cards, SPE Comput. Appl. 3, 6, 21-24.

30 Yang H.T., Mu L.M., Zeng Y.Q., Huang W., Xin H., Han E. (2014) Real time calculation of fluid level using dynamometer card of sucker rod pump well, International Petroleum Technology Conference, 10-12 December, Kuala Lumpur, Malaysia.

31 Liu X.F., Qi Y.G., Hu A.M., Zhao P.H., Liu C.H. (2011) Inflow performance analysis of single-phase water flow in coalbed methane wells, China J. Rock Mech. Eng. 30, 5, 960-966.

32 Vicki A.H., Paul S.S. (2002) A guide to coalbed methane operations, Gas Research Institute, Alabama, Birmingham.

Manuscript submitted in October 2016

Manuscript accepted in April 2017

Published online in June 2017

Cite this article as: X. Liu, C. Liu and Y. Yang (2017). Dynamic Behavior of the Polished Rod for the Coalbed Methane Pumping Installations, Oil Gas Sci. Technol 72, 16. 